\title{
Princípios para o currículo de um curso de Química
}

\author{
FLAVIO ANTONIO MAXIMIANO ${ }^{I}$
}

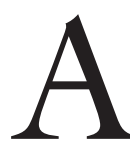

QUímICA é uma ciência básica da natureza. Ao se dedicar à compreensão da natureza submicroscópica da matéria e suas transformações, desenvolve uma linguagem própria e produz um conhecimento fundamental sobre a natureza. Conhecimento que é base para a edificação de outras áreas e profissões. Assim, a química é uma ciência desenvolvida por cientistas que são formados em cursos de nível superior. A química é também uma atividade industrial de natureza tecnológica. A indústria de transformação química produz diversos insumos essenciais para a sociedade contemporânea. Assim, faz-se necessária a presença de profissionais no setor produtivo que dominem essas técnicas e permitam a produção e o desenvolvimento tecnológico da área. A química igualmente é eleita como uma disciplina escolar. Sua natureza como conhecimento básico a levou junto com outras ciências da natureza a compor o cabedal de conhecimentos básicos de qualquer cidadão, quer seja para ler e compreender o mundo natural ou transformado pela mão do homem, quer seja para se continuar os estudos em nível superior ou técnico em outras áreas ou profissões. Assim, são necessários professores que tenham amplo domínio desse conhecimento para atuarem na Educação Básica, enfrentando os desafios e a complexidade que esta atividade exige.

Dessa breve descrição sobre a química pode-se inferir que é no Ensino Superior dessa disciplina acadêmica e atividade produtiva que serão formados três profissionais diferentes: o cientista, o químico e o professor. Uma instituição de ensino pode se propor a formar apenas um desses profissionais. No entanto, uma instituição como o Instituto de Química da Universidade de São Paulo (IQUSP) tem, desde suas origens, se preocupado com a formação de quadros para essas três atividades profissionais. O que traz para essa instituição um desafio ainda maior.

O presente artigo procura descrever os princípios que nortearam o desenvolvimento da atual proposta curricular dos cursos de graduação do Instituto de Química da Universidade de São Paulo. Trata-se de um relato da estrutura curricular em si, dos desafios que se apresentavam à graduação naquele momento e de uma reflexão do que ainda é preciso alcançar na visão de alguém que participou diretamente do processo de elaboração da proposta. Não se procura aqui relatar o processo de elaboração e implementação de um currículo com detalhes, nem de apresentar uma análise minuciosa dos resultados até aqui obtidos. 
Pretende-se apenas compartilhar uma visão pessoal de um processo específico, vivido em uma instituição específica, mas que pode ajudar na reflexão de aspectos gerais que envolvem as definições de um curso de graduação em Química.

\section{Os antecedentes da proposta de mudança curricular}

$\mathrm{Na}$ ocasião do processo de reforma curricular o IQUSP apresentava três opções distintas de cursos de graduação em Química cada um deles como uma opção distinta de ingresso. No período integral o curso de Bacharelado e Licenciatura em Química, com sessenta vagas, e no período noturno os cursos de Bacharelado em Química Ambiental e Licenciatura em Química, ambos com trinta vagas cada.

A estrutura curricular do curso do período integral estava vigente desde 2001. Na ocasião pretendia-se uma estrutura curricular mais flexível de modo a atender as diferentes aspirações profissionais dos alunos. Assim, foi montada uma estrutura prevendo a existência de um núcleo básico, contendo disciplinas comuns a qualquer uma das quatro modalidades formativas na época oferecidas (Bacharelado, Licenciatura, Bacharelado com Atribuições Tecnológicas e Bacharelado com Atribuições Biotecnológicas), a existência de um núcleo específico para cada modalidade e uma certa carga horária menor em disciplinas optativas livres que poderiam ser compostas por qualquer disciplina de graduação oferecida pela USP, incluindo as específicas para cada uma das quatro modalidades. Para o curso de Bacharelado, por exemplo, a carga horária é distribuída em 117 créditos em disciplinas do núcleo básico (cursadas até o quarto semestre), 69 créditos em disciplinas do núcleo específico e 58 créditos em disciplinas optativas.

Em 2006 o curso de Licenciatura teve que passar por uma pequena reestruturação para se adaptar ao Programa de Formação de Professores da USP e às Resoluções do Conselho Nacional de Educação (Brasil, 2002a; 2002b). Apesar de na época ter se adequado às exigências legais, tais modificações ainda se encontravam longe do ideal e do espírito de um curso de formação de professores. Em 2008 se iniciou a modalidade Bacharelado em Química com Ênfase em Bioquímica e Biologia Molecular.

Os dois cursos do período noturno tiveram início em 2003. Originalmente com duração de quatro anos e meio, sofreram modificações já em 2009 passando para cinco anos. Tais modificações se fizeram necessárias para atender as diretrizes para a formação de professores acima citadas e para atender exigências feitas pelo Conselho Estadual de Educação para o curso de Bacharelado em Química Ambiental.

Esperava-se na ocasião da criação dos cursos do período noturno que não fossem meramente uma duplicação do curso já existente e que atendessem às necessidades de um público diferente daquele do período integral. Com o tempo, foi-se verificando que o perfil dos ingressantes nos dois períodos não era tão distinto assim. Vários alunos do curso de Licenciatura noturno manifesta- 
ram interesse em também obter o título de bacharel, os processos internos de transferência de curso chegaram a registrar o interesse de mais de um terço dos ingressantes da Licenciatura noturno na mudança para os Bacharelados na expectativa de terem melhores opções no mercado de trabalho. Também os alunos do curso de Bacharelado em Química Ambiental passaram a manifestar interesse em cursar disciplinas de química tecnológica no período integral. Por serem cursos com estruturas curriculares distintas e com ingresso próprio via vestibular, o fluxo de alunos entre os dois períodos ou entre alunos dos dois cursos do período noturno era muito dificultado. Ao colar grau em um dos cursos do período noturno, o aluno tinha sua matrícula na universidade encerrada, o que não acontecia com o aluno do período integral que podia cursar mais de uma ênfase ou habilitação. Isso era percebido pelos alunos do período noturno como uma grande desvantagem já que seus colegas do período integral tinham mais opções formativas. Outro problema verificado se deve ao fato de que algumas disciplinas não eram equivalentes, e nas que eram, os alunos de um período não podem se matricular diretamente no outro, tendo sempre que pedir matrícula via requerimento.

Um outro problema sério dizia respeito às dificuldades observadas quanto ao registro profissional e atuação profissional dos egressos do curso de Bacharelado em Química Ambiental. Apesar de terem uma carga de estudos em química compatível com a formação de qualquer bacharel em química do país, esses alunos tiveram inicialmente restrições quanto a sua área de atuação estabelecida pelo Conselho Regional de Química devido ao nome do curso ser específico. Tal fato chegou a ser revertido após intervenção do IQUSP junto ao Conselho Federal de Química.

Tais fatos passaram a causar desconforto dentro da instituição a respeito da separação das possibilidades formativas dos diferentes cursos e levaram a uma proposta que buscasse resolver tais questões.

Sobre o Projeto Pedagógico vigente para o curso integral, passados mais de dez anos de sua implantação, fez-se necessário reconhecer que certos objetivos previstos não foram plenamente alcançados e as pequenas alterações que foram sendo feitas ao longo do tempo, levaram ao acúmulo de certos problemas que precisaram naquele momento ser sanados. Dentre esses problemas, podem-se enumerar: 1) $\mathrm{O}$ não oferecimento sistemático de disciplinas optativas pelo IQ, ou a baixa frequência pelos nossos alunos das poucas optativas que foram oferecidas. Ou seja, a falta de uma cultura de disciplinas optativas tanto no IQ como na universidade como um todo, isto é, a falta de uma tradição que leve em conta uma formação individualizada do aluno leva-os a buscar optativas apenas para cumprir as horas exigidas; 2) A licenciatura passou a ser efetivamente um mero complemento ao bacharelado; 3) As disciplinas de Físico-Química já começavam a ser tratadas a partir do segundo semestre do curso, antes que o aluno tivesse tido contato com o conhecimento de cálculo necessário; 4) A proposta 
previa que o curso fosse dividido em dois anos básicos contendo aquilo que deveria ser definido como conhecimento químico essencial e básico. Do ponto de vista do planejamento, essa premissa se baseava na ideia de currículo em espiral, onde o aluno, em um primeiro momento, devia ver os conceitos e as teorias de uma forma mais introdutória (básica). Em outros momentos (ou disciplinas) os temas são reapresentados sempre em um nível mais profundo e integrado a outros conceitos. No entanto, com o passar do tempo o que ocorreu é que um excesso de conteúdo foi se acumulando nesses dois primeiros anos. O terceiro semestre do curso chegou a ter uma carga de 34 horas-aula distribuídas em sete disciplinas concomitantes. Enquanto isso, nos quinto e sexto semestres houve um número reduzido de disciplinas com uma grande quantidade de créditos cada. Havia, portanto, um acentuado desequilíbrio na distribuição de créditos e, principalmente, de conteúdos ao longo de todo o curso.

Diante do exposto e após quase dez anos de existência entre cursos distintos, colocou-se a questão de se rever os objetivos e fundamentos que orientaram a criação dos cursos no passado, buscando simplificar a graduação e, ao mesmo tempo, atender as demandas manifestadas por nossos estudantes. Assim, coube à Coordenação do Curso trabalhar a partir de $2012 \mathrm{em}$ uma nova proposta curricular orientada por certos princípios que levassem a uma nova estrutura curricular implementada a partir de 2014.

\section{Princípios e diretrizes que nortearam a proposta de alteração curricular do IQUSP}

Tendo em vista aspectos anteriormente apontados, podem-se elencar algumas perspectivas, ou mesmo princípios mais gerais, que orientaram a elaboração do Projeto Pedagógico do curso. Tais princípios gerais podem ser elencados em:

i) O IQUSP, tendo em vista sua história na formação e consolidação da Ciência Química brasileira, em consonância com a importância histórica da própria Universidade de São Paulo, assume a função de formar quadros profissionais para a pesquisa acadêmica, para a docência na educação básica e para o setor produtivo (indústria e serviço).

ii) Cada uma dessas diferentes atividades profissionais exige uma formação específica que deve ser traduzida em uma estrutura curricular própria contendo disciplinas específicas e diferentes oportunidades de experiência no tocante à formação profissional, principalmente no que concerne a estágios quer seja em escolas, indústrias ou iniciação à pesquisa científica.

iii) Independentemente das diferentes necessidades formativas, deve-se garantir a todos os alunos uma sólida formação em química que se traduz em um núcleo comum de disciplinas básicas e gerais em cada uma das diferentes áreas tradicionais da química.

iv) A escolha pela atuação profissional específica e, consequentemente, pelo percurso formativo dentro do curso de graduação não deve ser feita pelo aluno na ocasião da inscrição para o vestibular e muito menos ser definitivo 
de forma a excluir ou dificultar possibilidades de mudanças ao longo de seus estudos. Assim, o aluno deve ter uma maior liberdade de escolha durante seu percurso formativo e, principalmente, na etapa final de seu curso.

v) Independentemente da escolha profissional é importante possibilitar ao aluno que componha parte de seu percurso formativo com disciplinas de seu interesse. Desde disciplinas de caráter mais geral de outras áreas do conhecimento ou de temas mais avançados e específicos do universo da química.

Desses princípios seguiram as diretrizes que compõem a estrutura curricular ora vigente, cujos aspectos mais relevantes são aqui apresentados.

A fim de garantir a escolha profissional do aluno após o ingresso na Universidade os três diferentes cursos foram unificados um uma única carreira denominada química - Bacharelado e Licenciatura que, por sua vez, foi dividida em dois únicos cursos, o do período integral e o do período noturno, ambos disponibilizando 60 vagas e denominados por Bacharelado e Licenciatura em Química. ${ }^{1}$ Os dois cursos possibilitam ao aluno a obtenção dos títulos de bacharel e licenciado de maneira que o aluno possa escolher por apenas um título ou optar por obter os dois diplomas correspondentes, desde que cumpra todas as exigências previstas para os dois cursos. ${ }^{2} \mathrm{O}$ aluno que optar pelo curso de Bacharelado em Química também pode agregar conhecimento em uma determinada ênfase dentre as especialidades oferecidas pelo IQUSP ou a habilitação em Química Tecnológica equivalente, em termos de habilitação profissional, ao que outros cursos denominam por Química Industrial. O Quadro 1 apresenta as diferentes opções formativas para os cursos dos dois períodos. ${ }^{3}$

Quadro l - Opções de curso de graduação oferecidas hoje pelo IQUSP

\begin{tabular}{|l|l|l|}
\hline Curso & $\begin{array}{l}\text { Bacharelado e Licenciatura } \\
\text { em Química - Integral }\end{array}$ & $\begin{array}{l}\text { Bacharelado e Licenciatura } \\
\text { em Química - Noturno }\end{array}$ \\
\hline Tempo ideal & Oito semestres & 10 semestres \\
\hline $\begin{array}{l}\text { Opções } \\
\text { formativas }\end{array}$ & $\begin{array}{l}\text { Licenciatura em Química } \\
\text { Bacharelado em Química } \\
\text { Bacharelado em Química com ênfase } \\
\text { em Bioquímica e Biologia Molecular } \\
\text { Bacharelado em Química } \\
\text { com Atribuições Tecnológicas } \\
\text { Bacharelado em Química com } \\
\text { Atribuições em Biotecnologia }\end{array}$ & $\begin{array}{l}\text { Bacharelado em Química } \\
\text { Bachadado em Química } \\
\text { comfase em Química } \\
\text { Ambiental }\end{array}$ \\
\hline
\end{tabular}


Essa organização permite que os candidatos ao curso de Graduação possam optar pela carreira em química de uma forma geral e não pelo direcionamento profissional antes de ingressar efetivamente no curso e na Universidade. A perspectiva aqui é de que uma escolha mais específica requer vivência acadêmica e maior maturidade que não pode ser cobrada de um recém-egresso da Educação Básica. Permite-se assim que o aluno possa, por exemplo, experimentar diferentes disciplinas específicas, conhecer melhor o curso e refletir melhor sobre suas aptidões antes de optar pela profissão (professor, químico ou cientista) que pode então ser feita com maior conhecimento sobre a profissão específica, suas possibilidades de atuação, mercado de trabalho, empregabilidade e características próprias de seu exercício.

Para ingressar no curso de Licenciatura o aluno deve se matricular em uma das disciplinas de Iniciação à Licenciatura que são as disciplinas de Introdução aos Estudos da Educação da Faculdade de Educação da USP (FEUSP) e a de Introdução ao Ensino de Química, oferecida pelo IQUSP. Esta última é oferecida na grade curricular ideal no $3^{\circ}$ semestre para o período integral e $4^{\circ}$ semestre para o período noturno, de maneira que para o aluno que já tenha decidido pelo magistério antes mesmo de ingressar na universidade não há prejuízo no tempo necessário para sua formação. Toda a grade horária do curso de Licenciatura foi elaborada de maneira a distribuir as disciplinas específicas ao longo do curso de modo que a formação docente não se dê na etapa final do mesmo, de acordo com as diretrizes vigentes para a formação de professores (Brasil, 2015; São Paulo, 2017; USP, 2004). Alternativamente a opção pela licenciatura também pode ser feita em qualquer semestre do curso de graduação, mesmo para alunos que já tenham obtido o título de bacharel e ocorre no momento em que o aluno efetiva sua matrícula em uma das disciplinas citadas acima ou em qualquer outra disciplina específica do curso de Licenciatura.

O fato de o curso de Licenciatura não ser totalmente separado do Bacharelado também permite que o aluno possa obter os dois diplomas sem que precise prestar outro exame vestibular ou tenha que pedir matrícula como graduado de nível superior. Também permite a um aluno que já tenha obtido o título de bacharel em química pelo IQUSP e queira então obter o título de licenciado em química possa fazê-lo. ${ }^{4}$ Com isso, é esperado diminuir a pressão por vagas do curso de Bacharelado e a desistência precoce da Licenciatura, observadas pelo expressivo número de alunos que pediam transferência interna do antigo curso de Licenciatura noturno.

Da mesma forma que para a escolha entre o bacharelado e a licenciatura, a escolha entre as diferentes modalidades ou ênfases do bacharelado (Quadro 1) pode também ser feita em qualquer momento da trajetória acadêmica do aluno. Nessa perspectiva, diferente do que se tinha para o curso integral anterior, procurou-se evitar que todo o conteúdo básico de química fosse abordado na primeira metade do curso, deixando a especialização para o final. Isso foi mais 
um desafio principalmente no tocante à compatibilização entre a licenciatura e o bacharelado, uma vez que as diretrizes de formação de professores (Brasil, 2015) e o consenso da área (Ferreira; Kasseboehmer, 2012) indicam a necessidade de romper com o modelo curricular onde primeiro se aprende o conteúdo a ensinar e depois esse é completado com o conhecimento pedagógico que forma o professor. ${ }^{5}$

Para garantir que o aluno tenha uma maior liberdade de escolha e possa construir um percurso formativo próprio, de acordo com seus interesses e aptidões, o projeto pedagógico permite uma total flexibilidade para que o aluno escolha também entre as diferentes opções de cursos que o IQ oferece, independentemente do período (integral ou noturno) a que está matriculado. Assim, um aluno do período noturno poderá fazer, por exemplo, as disciplinas das Atribuições Tecnológicas ou a ênfase em Bioquímica, sem que tenha que pedir transferência de curso. Já um aluno do período integral também poderá fazer facilmente as disciplinas específicas da ênfase em Química Ambiental. Um aluno do período integral também pode cursar as disciplinas do curso de Licenciatura (em parte ou em sua totalidade) no período noturno, diminuindo o tempo necessário para a integralização das disciplinas dos dois cursos. É evidente que para alunos do período noturno que trabalhem durante o dia suas opções são bem mais restritas. Nesse caso o aluno tem como opções apenas aquelas apresentadas no Quadro 1, e as disciplinas optativas do bacharelado são as da licenciatura ou disciplinas de outra unidade oferecidas no período noturno que sejam compatíveis com a grade horária do aluno.

A carga horária total tanto para o curso de Bacharelado como para o de Licenciatura foi estabelecida em 3.000 horas em atividades presenciais em sala de aula ou laboratório. Esse valor equivale a exatamente 20 horas por semana em um curso noturno durante cinco anos. Assim, a média para o curso integral ficou em 26 horas por semana. Para evitar sobrecarga em determinado semestre foi estabelecido também que em cada semestre não se deveria ter mais do que 5 ou 6 disciplinas por semestre no curso integral e 4 ou 5 para o curso noturno. ${ }^{6}$ Foram extintas as aulas aos sábados para o curso noturno, tendo em vista que essas sobrecarregavam o tempo disponível dos alunos. Desejava-se, para os dois períodos, uma carga horária em aulas que permitisse aos alunos tempo para estudos individuais ou em grupos.

Uma inovação que se buscou nesse projeto pedagógico foi a inclusão em cada uma das disciplinas de horas atividades extraclasse que totalizam mais 1.000 horas. Definiu-se que a cada quatro horas de aula presencial seriam atribuídas nas disciplinas 2 horas em atividades de trabalho independente. Essa ação procurou indicar para aos alunos a necessidade de manter um estudo semanal contínuo dos conteúdos apresentados em sala. Para os professores, procurou indicar a necessidade de planejar atividades contínuas para os alunos. A efetivação desse tipo de atitude tanto da parte de alunos como da de docentes depende 
certamente de uma mudança cultural ainda longe de ser realidade. No entanto, foi entendimento que esses princípios deveriam ser explicitados e o tempo a isso dedicado deveria ser computado na carga horária de maneira a não só indicar como reconhecer as atividades e iniciativas que vão neste sentido. A delimitação da carga horária em aulas semanais tinha por objetivo dar condições efetivas de mudanças nessa cultura. ${ }^{7}$

Outro importante aspecto relacionado à liberdade de escolha dos alunos é que foi criada uma série de disciplinas optativas eletivas e optativas livres. Disciplinas optativas eletivas foram definidas como aquelas de natureza química. São disciplinas que abordam um conteúdo químico mais específico ou mais avançado. Seu papel é o de garantir profundidade e, ao mesmo tempo, diversidade na formação em especial do bacharel em química, principalmente na modalidade de bacharel puro sem ênfase específica. Nesse caso, a carga horária total para esse tipo de disciplina é de 420 horas ( $14 \%$ do curso). A fim de garantir um oferecimento variado de disciplinas dessa natureza, foram criadas disciplinas para a graduação que refletem as ementas de disciplinas da pós-graduação em química, caso os docentes envolvidos entendam a pertinência dessa ação. Assim, um professor escalado para essa disciplina tem parte de sua turma composta por alunos de pós-graduação e parte formada por alunos de graduação em estágio avançado. ${ }^{8}$ Isso permite garantir um bom número de disciplinas eletivas sem aumentar substancialmente a carga didática docente e sem duplicar o oferecimento de conteúdos, o que não teria sentido. Foi uma forma de sanar a dificuldade encontrada no projeto pedagógico anterior que foi justamente a falta de disciplinas dessa natureza. Ainda são também consideradas disciplinas eletivas aquelas obrigatórias para as habilitações ou ênfases. Assim, um aluno também pode escolher cursar parte das disciplinas específicas para a ênfase em Bioquímica e Biologia Molecular e parte das disciplinas de Química Ambiental. ${ }^{9}$

Como disciplinas optativas livres são consideradas quaisquer disciplinas de graduação oferecidas pela Universidade de São Paulo ou as disciplinas consideradas eletivas. O objetivo é garantir, de acordo com o interesse do aluno, uma diversidade formativa mais ampla. No caso do bacharelado a carga horária total para esse tipo de disciplina é de 300 horas ( $10 \%$ do curso) e cai para as demais opções formativas. ${ }^{10}$

Para o bacharel em química puro a soma de disciplinas eletivas e livres corresponde a cerca de $24 \%$ da carga horária. Esse percentual cai drasticamente quando o aluno opta por uma habilitação ou ênfase, uma vez que essa sua escolha em si já constitui em uma especialização. Para a licenciatura, tendo em vista as múltiplas exigências estabelecidas nas diretrizes curriculares (Brasil, 2015; São Paulo, 2017) e no Programa se Formação de Professores da USP (USP, 2004) não há exigência de disciplinas eletivas e o total de optativas livres cai para apenas 120 horas.

$\mathrm{Na}$ montagem das grades curriculares procurou-se estabelecer uma alter- 
nância entre os semestres do ano para o oferecimento da maioria das disciplinas obrigatórias no curso integral e noturno. Por exemplo, a disciplina Química Analítica I é oferecida no primeiro semestre do ano para o período integral e no segundo semestre no período noturno. Dessa forma o aluno do período integral que porventura venha a ser reprovado nessa disciplina pode cursá-la novamente no período noturno. Com isto se espera diminuir o tempo médio de titulação ao evitar que os alunos esperem um ano para cursar uma disciplina em que tenha sido reprovado.

Uma das grandes preocupações e motivo para inúmeros debates no grupo que elaborou a proposta pedagógica foi garantir que os cursos fossem compostos por uma série de conhecimentos básicos e fundamentais, presentes nas diferentes sub-áreas da química, distribuídos ao longo de toda a formação do aluno e não concentrado em uma determinada etapa, como no início do curso. Esses conhecimentos básicos foram agrupados em um conjunto de disciplinas denominado de núcleo básico, uma vez que as específicas para as habilitações ou ênfases constituem o denominado núcleo específico. ${ }^{11} \mathrm{O}$ núcleo básico tem uma carga horária total de 2.265 horas (cerca de $75 \%$ do total) para o curso de bacharelado e compõe as disciplinas denominadas como Química Geral e as demais sub-áreas tradicionais da química. ${ }^{12}$

As disciplinas de Química Geral tiveram uma preocupação maior por serem essas as que iniciam os cursos e apresentam aos alunos os conceitos fundamentais e básicos da química. A opção foi que os conteúdos denominados como Química Geral fossem todos tratados ao longo de todo o primeiro ano para o curso integral e ao longo dos primeiros três semestres para o curso noturno de forma a garantir tempo suficiente para o aprendizado de conteúdos tão fundamentais. ${ }^{13}$ Tais conteúdos foram distribuídos em três disciplinas, duas com 6 horas semanais em aulas teóricas e 4 horas em aulas práticas e uma terceira com 2 horas teóricas e 2 experimentais. Na primeira disciplina (Química Geral I) são abordados, na parte teórica, os conteúdos relacionados à natureza atômico-molecular da matéria (modelos de estrutura atômica, teorias de ligação química e interações intermoleculares). Já nas aulas experimentais são apresentados prioritariamente, sem prejuízo de outros conteúdos, aspectos básicos relacionados às reações químicas tais como, os principais tipos de reação aspectos qualitativos e quantitativos (estequiometria, rendimentos etc.) envolvidos, relações entre as observações macroscópicas desses fenômenos com as explicações microscópicas e representações (equações químicas) dos mesmos. Na disciplina seguinte, Química Geral II, são abordados os aspectos teóricos relacionados às reações químicas de acordo com o que vem sido apresentado em propostas contidas em livros-didáticos mais recentes (Atkins; Jones, 2007; Burrows et al., 2009). Aqui são apresentados conceitos da termodinâmica química (espontaneidade, entropia, entalpia, energia livre), o equilíbrio químico é então introduzido a partir do suporte da termodinâmica. Seguem os conceitos de eletroquímica e cinética 
química. Também são introduzidos conceitos iniciais da química orgânica (estrutura de compostos orgânicos, aplicações da teoria de orbitais moleculares, estereoquímica e acidez e basicidade de compostos orgânicos), uma vez que as disciplinas dessa área tiveram uma maior redução na carga horária. A parte experimental complementa esses conteúdos e procura, principalmente, desenvolver a habilidade de relatar formalmente resultados experimentais. A terceira disciplina (Química Analítica I) aborda através dos tradicionais métodos de análise química qualitativa conceitos de equilíbrio químico em solução aquosa. Tal proposta de conteúdo foi definida após a aprovação da estrutura curricular através de várias reuniões com os docentes envolvidos. Não se trata de uma proposta definitiva visto que sempre deve ser revista à luz da experiência de aplicação e dos resultados obtidos.

Em nossa opinião, cabe uma discussão mais ampla e profunda do papel pedagógico que os conteúdos tratados nas disciplinas de Química Geral, no entanto o aprofundamento necessário foge aos objetivos do presente texto. Apenas como introdução ao problema cabe mencionar que a tradição no Brasil está em basear tais disciplinas em textos didáticos de origem estrangeira, mais notadamente norte-americana. Evidente que o que se conceituou historicamente em denominar conhecimento em química geral tem um caráter universal e, sem dúvida, é a base de partida para um curso brasileiro ou de qualquer canto do mundo. Entretanto, com as mudanças que vêm sendo colocadas para o Ensino Médio brasileiro, ${ }^{14}$ tanto as que já se apresentaram no passado recente, cujo foco se dirigiu mais para a formação geral de um cidadão através do desenvolvimento de competências e habilidade (Brasil, 1999), como as que se apresentam para o futuro com a reforma do Ensino Médio e com a Base Nacional Curricular Comum (Brasil, 2018), já apresentadas e hoje em debate, ${ }^{15}$ caminhamos para uma realidade onde fica aberta a questão sobre o que se poderá considerar como conhecimento químico básico já aprendido pelos ingressantes em um curso universitário dada a diversidade de sistemas de ensino ou mesmo se tal reforma atinge seus objetivos.

As demais disciplinas que compõem o núcleo comum são, como já citado, aquelas pertencentes às sub-áreas da química. De maneira geral, a carga horária total para cada uma dessas ficou em torno de 16 horas/semana distribuídas ao longo do curso entre aulas teóricas e experimentais. Na forma de organizar as atividades teóricas e experimentais prevaleceu a tradição da instituição. Assim, algumas sub-áreas trabalham com disciplinas compostas por uma parte teórica e outra experimental como as de química analítica e química inorgânica; em outras como as de físico-química, química orgânica e bioquímica, as disciplinas experimentais são separadas das disciplinas teóricas. Também a distribuição de conteúdos seguiu, em geral, o que vinha sendo trabalhado ao longo dos últimos anos com pequenas alterações que, em alguns casos, foram ajustadas ao longo da implementação. ${ }^{16}$ 
A questão do que vem a ser conteúdo básico para cada disciplina ou cada sub-área não é um tema simples e, pode-se afirmar, está longe de um consenso. Na verdade, os conteúdos de ensino, em qualquer nível, têm sido definidos largamente pelo que se sistematiza em manuais didáticos, que há muito se constituem em longos compêndios que sobrecarregam as aulas expositivas e o tempo de dedicação dos alunos.

Como então definir o que seja básico para uma disciplina? Sem dúvida tal questão é e sempre será pertinente. Acreditamos que a resposta deve ser preocupação de cada docente. No entanto, é preciso que as possíveis respostas e posições não fiquem restritas ao trabalho individual, isolado e dentro da disciplina específica. Precisam ser compartilhadas por todos os docentes envolvidos em disciplinas afins e até mesmo nas demais disciplinas que compõem o curso. Trata-se de uma construção de consensos ou perspectivas contínua, onde em momentos de sínteses provisórias tomam forma em um currículo. Devem então ser aplicados e avaliados. Promovendo uma reflexão que leva a um novo e crítico reposicionamento do conteúdo. Nesse processo é preciso ter em vista que ensinar significa fazer escolhas. É preciso ficar atento a possíveis lacunas e evitar também repetições de conteúdo que muitas vezes acontecem em um mesmo nível de profundidade. Tal atividade, em geral, ainda está longe do dia a dia das universidades brasileiras.

Tais reflexão e aprofundamento não foram possíveis de ser feitos ao longo do processo de preparação do presente projeto pedagógico. O que o grupo envolvido com ele pôde fazer naquele momento foi definir um teto de carga horária para cada sub-área (as 16 horas anteriormente citadas). Algumas discussões ocorreram naquele momento e outras no andar da implementação do currículo. ${ }^{17}$ Sem dúvida, é desejável que tais inciativas sejam institucionalmente favorecidas.

Outro aspecto que se buscou contemplar na reforma curricular foi estabelecer o menor número de pré-requisitos possível entre as disciplinas. Estabelecer uma grade curricular exige definir o encadeamento temporal das diferentes disciplinas que compõem o curso, ou seja, definir em qual semestre se encaixa determinada disciplina, o que vem antes, o que vem depois dela e o que é ensinado concomitantemente. Nesse processo sempre se levam em conta os conhecimentos prévios necessários ou desejáveis que tradicionalmente se constituem na adoção de pré-requisitos obrigatórios, de forma que o aluno deve ter sido aprovado nas disciplinas consideradas requisitos para se matricular na disciplina em questão. A experiência mostra que um currículo com disciplinas amarradas em muitos pré-requisitos pode provocar efeitos indesejáveis no percurso de muitos alunos. Longo tempo de formação e situações em que o aluno não tem matrícula em um número razoável de disciplinas por não ter os pré-requisitos necessários entre outras. ${ }^{18} \mathrm{~A}$ opção encontrada foi deixar um número mínimo de requisitos restrito apenas a disciplinas realmente subsequentes e, majorita- 
riamente, dentro de uma mesma sub-área. No entanto, optou-se por indicar a necessidade de certos conhecimentos prévios explicitamente na ementa da disciplina. Cabe ao aluno, dentro do espírito de liberdade acadêmica proposta no projeto, avaliar seu conhecimento prévio e decidir se se matricula ou não.

$\mathrm{Na}$ tentativa de se garantir uma articulação real entre as diferentes disciplinas e áreas da química, o projeto pedagógico propõe que as disciplinas do núcleo básico são organizadas em módulos didáticos com o objetivo de integrá-las de acordo com objetivos formativos específicos. Cada módulo deve ter um coordenador, dentre os docentes escalados para as disciplinas que o compõe. Os docentes deveriam se reunir periodicamente para definir os objetivos formativos e as habilidades específicas do respectivo módulo, discutir os planejamentos das disciplinas e a avaliação das mesmas (Quadro 2).

\section{Novos desafios e perspectivas para além de uma mudança de grade curricular}

O presente Projeto Pedagógico teve sua implementação iniciada em 2014. Passados cinco anos, cabe verificar quais das perspectivas foram atingidas e quais necessitam ser reavaliadas. No entanto, dados objetivos necessários para avaliar as intenções expressas nos currículo sobre, por exemplo, tempo de titulação, matrículas em disciplinas optativas livres e eletivas, trânsito dos alunos entre os dois períodos, ainda não foram sistematizados. ${ }^{19}$ De qualquer forma, cabe aqui uma reflexão, mesmo que muito pessoal, sobre a proposta e seus objetivos que vão além da estrutura curricular e podem aqui ser apontados como necessários para os próximos passos da instituição, no sentido de aprimorar seu curso de graduação.

Por mais tempo e discussões que a elaboração de uma proposta curricular exija. Por mais embates e engajamento que isso possa provocar dentre os membros de uma instituição de Ensino Superior, mesmo que só em parte desses, o desafio da elaboração de uma proposta, em nossa opinião, não se compara aos desafios que podem exigir sua implementação, principalmente quando se necessita de revisão e modificação de culturas instaladas pela tradição. Culturas que levam a práticas, tanto por parte do corpo docente como por parte do corpo discente, que inevitavelmente são objetos de críticas durante um processo de reestruturação curricular. Assim, três aspectos aqui passam a ser abordados: a organização da estrutura curricular em módulos, o incentivo a um estudo mais contínuo por parte dos alunos e os métodos de ensino aplicados em aulas. Os dois primeiros foram de certa forma abordados e contemplados na proposta, o último ainda não, e ainda não foi atacado de forma institucional, embora no âmbito individual alguns docentes podem ter se dedicado a essa questão.

A organização das diferentes disciplinas do núcleo básico em módulos ficou longe de ser efetivamente implementada. Nos primeiros dois anos foram feitos esforços principalmente na organização do Módulo I que levou à organização conceitual já descrita acima. Nos demais módulos as tentativas foram 
Quadro 2 - Organização das disciplinas básicas do curso de Bacharelado em módulos

\begin{tabular}{|c|c|c|}
\hline $\begin{array}{l}\text { Módulo I: } \\
\text { Fundamentos } \\
\text { da Química }\end{array}$ & $\begin{array}{l}\text { Os conceitos fundamentais são apresentados } \\
\text { ao longo do primeiro ano de forma qualitativa, } \\
\text { sem um formalismo matemático ou teórico } \\
\text { profundo. São as disciplinas introdutórias ao } \\
\text { curso e ao conhecimento químico. São tratadas } \\
\text { nos primeiros semestres do curso, introduzem } \\
\text { o aluno na linguagem química e constituem } \\
\text { a base de conteúdos que serão aprofundados } \\
\text { nas etapas seguintes. O tempo de dedicação ao } \\
\text { conteúdo destas disciplinas deve ser suficiente } \\
\text { para permitir que o aluno domine o mesmo } \\
\text { e tenha clareza quanto a sua importância. }\end{array}$ & $\begin{array}{l}\text { Química Geral I; } \\
\text { Fundamentos da Química } \\
\text { Experimental; } \\
\text { Química Geral II; } \\
\text { Química Analítica I } \\
\text { e Introdução à Bioquímica. }\end{array}$ \\
\hline $\begin{array}{l}\text { Módulo II: } \\
\text { Ciências } \\
\text { complementares }\end{array}$ & $\begin{array}{l}\text { São as disciplinas de Matemática e Física } \\
\text { necessária para a formação básica de qualquer } \\
\text { químico uma vez que são básicos para } \\
\text { o domínio de conteúdos químicos mais } \\
\text { avançados. }\end{array}$ & $\begin{array}{l}\text { Cálculo I para Química; } \\
\text { Cálculo II para Química; } \\
\text { Cálculo III para Química; } \\
\text { Álgebra Linear; } \\
\text { Laboratório de Física; } \\
\text { Física I; Física III; Física IV } \\
\text { e Noções de Estatística. }\end{array}$ \\
\hline $\begin{array}{l}\text { Módulo III: } \\
\text { Conteúdos } \\
\text { básicos }\end{array}$ & $\begin{array}{l}\text { Neste módulo o conhecimento químico } \\
\text { começa a ser abordado nas áreas tradicionais } \\
\text { da química. As disciplinas formam a base de } \\
\text { um conhecimento químico mais especializado. }\end{array}$ & $\begin{array}{l}\text { Estrutura e Propriedades } \\
\text { de Compostos Orgânicos; } \\
\text { Química Inorgânica I: } \\
\text { Química dos Elementos; } \\
\text { Físico Química I; } \\
\text { Química Analítica II } \\
\text { e Bioquímica Metabólica. }\end{array}$ \\
\hline $\begin{array}{l}\text { Módulo IV: } \\
\text { Conteúdos } \\
\text { específicos }\end{array}$ & $\begin{array}{l}\text { Este módulo complementa o anterior, } \\
\text { aprofundando os conhecimentos de cada } \\
\text { especialidade química. }\end{array}$ & $\begin{array}{l}\text { Físico Química II; } \\
\text { Reatividade de Compostos } \\
\text { Orgânicos; } \\
\text { Biologia Molecular; } \\
\text { Química Analítica III; } \\
\text { Físico Química III; } \\
\text { Espectroscopia e Química } \\
\text { Inorgânica II: } \\
\text { Química de Coordenação. }\end{array}$ \\
\hline $\begin{array}{l}\text { Módulo IV: } \\
\text { Formação } \\
\text { em Química } \\
\text { Experimental }\end{array}$ & $\begin{array}{l}\text { A experimentação é uma atividade fundamental } \\
\text { na formação do químico. Este módulo } \\
\text { composto por disciplinas eminentemente } \\
\text { experimentais que tratam de aspectos } \\
\text { correlacionados a medidas de propriedade } \\
\text { químicas, síntese e análise de compostos } \\
\text { químicos. }\end{array}$ & $\begin{array}{l}\text { Bioquímica Experimental; } \\
\text { Físico Química Experimental; } \\
\text { Química Orgânica Experimental; } \\
\text { Química Experimental Avançada } \\
\text { e Introdução à Tecnologia } \\
\text { ou à Pesquisa Científica I. }\end{array}$ \\
\hline
\end{tabular}


incipientes e até mesmo frustrantes. A falta de uma cultura institucional de avaliação e planejamento conjunto do ensino está, em nossa opinião, como fator principal que dificulta uma coordenação efetiva entre disciplinas paralelas e não subsequentes. ${ }^{20}$ No Ensino Superior o planejamento pedagógico ocorre num nível individual ou dentro da equipe que compõe uma mesma disciplina. Não há tradição de um planejamento mais amplo.

Uma das inovações tentadas na presente reforma curricular foi a de associar a cada disciplina uma carga horária em horas atividade com o objetivo de indicar aos alunos a necessidade de um estudo contínuo de cada componente curricular. Tradicionalmente os alunos assistem a aulas, fazem anotações durante elas, mas dedicam maior tempo aos seus estudos nas épocas que antecedem provas e exames. Isso não parece, a nosso ver, tão efetivo quanto um estudo mais contínuo dado que o aprendizado demanda tempo, não ocorre de uma única vez, exige tempo e recursividade. Muitas vezes os professores indicam uma extensa bibliografia no primeiro dia de aula. Algumas vezes entregam de imediato longas listas de questões para estudo para servirem aos alunos ao longo do semestre; outras, entregam listas ao longo do curso. Seriam tão efetivas tais estratégias? Dariam conta os alunos da bibliografia composta até por centenas de páginas e dezenas de questões?

O Ensino Médio brasileiro está largamente baseado em sistemas de ensino apostilados, com um conteúdo resumido e questões-padrão. Seriam os egressos desses sistemas capazes de lidar sozinhos e sem orientação com a quantidade de informação a que são de imediato submetidos? A quantidade de textos? É possível que um aluno ingressante na Universidade, mesmo oriundo de caros colégios, nunca tenha aberto um livro-texto de qualquer disciplina! E é agora que ele terá contato com extensas obras de referência, verdadeiros compêndios que, mesmo com preocupação didática típica de um texto de ensino universitário, devem ter suas centenas de páginas vencidas nas apenas quinze semanas que compõem um semestre letivo. Vale também contar a heterogeneidade da educação básica brasileira e do abismo entre a escola pública e privada, que implica heterogeneidade entre o corpo discente e importantes lacunas no conhecimento de muitos alunos. ${ }^{21}$ É preciso que os docentes universitários tomem consciência de tal realidade sobre o Ensino Médio. Do contrário, corremos o risco de cair em respostas simplistas sobre possíveis fracassos escolares de nossos alunos, como simples falta de dedicação desses quando a dedicação pode simplesmente estar mal direcionada.

Nesse cenário algumas inciativas, até mesmo simples, podem ser efetivas principalmente para as disciplinas do primeiro e talvez também do segundo ano do curso. Tais medidas teriam por objetivo orientar os alunos, promover experiências de estudo na expectativa de desenvolver autonomia e atitudes mais proativas perante seus próprios estudos e seu próprio aprendizado. Algo que também leva tempo. 
Dentre tais iniciativas por parte dos docentes podemos destacar a de definir claramente os objetivos instrucionais para cada tópico abordado, indicando o que se espera que o aluno seja capaz de fazer. ${ }^{22}$ Indicar claramente uma bibliografia a ser estudada o que implica selecionar partes mais fundamentais dos textos didáticos. Além de selecionar tais textos seria interessante dirigir os estudos dos alunos através de guias de estudo ou estudos dirigidos (Bordenave; Pereira, 2005) que chamem a atenção para o que é mais importante, que tragam problemas e questões que exijam por parte dos alunos tanto fazer uma análise do conteúdo, dos conceitos e procedimentos envolvidos como de fazer sínteses do material estudado. Não cabe aqui aprofundar e descrever com detalhes tais questões, mas afirmar que é preciso e urgente mudar a cultura de estudos e, consequentemente, as práticas de nossos alunos, mas a maioria deles pode não conseguir mudar essa cultura sozinhos e sem orientação pode até levar muito tempo nisso. Seria tão custoso tentar orientar e acelerar esse processo?

No caso da proposta curricular aqui apresentada, é importante que tais atividades levem em conta o tempo de duas horas semanais já previstas na própria grade curricular. Não é muito tempo quando se leva em conta uma única disciplina e o professor não pode se esquecer de que o aluno tem outras tantas no mesmo semestre. No entanto, não há dúvidas da necessidade e dos possíveis benefícios que um estudo contínuo seria capaz de promover no aprendizado.

Por fim, quanto às estratégias didáticas para o Ensino Superior, há sem dúvida muito a ser discutido e aprofundado que ultrapassa os objetivos aqui colocados. Certamente, a implementação dessas estratégias concorre também para desenvolver a autonomia do estudante.

Muitas propostas têm sido apresentadas na literatura, que vão desde aquelas que exigem uma total mudança na organização curricular, como os currículos baseados em PBL (problem based learning), quanto a propostas mais restritas como aquelas que propõem o método de sala de aula invertida (flipped classrom), onde o aluno deve estudar o conteúdo da disciplina antes da aula (Bergmann; Sams, 2018; Seery, 2015). Muitas propostas se baseiam em utilizar o próprio período de aulas para diminuir o tempo dedicado à exposição do conteúdo pelo professor e incluir atividades em que os alunos possam trabalhar em pequenos grupos com o objetivo de resolver problemas relevantes. O próprio IQUSP tem uma experiência significativa de um método de ensino ativo que é aplicado há décadas em parte das disciplinas de bioquímica oferecidas para diversos cursos da capital (Cicuto; Torres, 2016). De uma maneira geral, o que essas propostas de ensino procuram é inverter o foco da tradicional aula expositiva, largamente presente em cursos superiores, do processo de ensino (centrado no professor) para o processo de aprendizado (centrado no aluno). Essas mudanças são verdadeiras mudanças paradigmáticas no ensino de graduação. Devem ser consideradas não apenas no âmbito do trabalho individual de cada docente, mas devem ser verdadeiramente incentivadas pela instituição. ${ }^{23}$ 


\section{Conclusão}

Qualquer processo de mudança curricular exige reflexão, discussão e engajamento institucional. É preciso avaliar de onde se vem, quais as características da instituição, seus prontos fortes, suas tradições e experiências, para não se propor algo inatingível e inviável. É também preciso ter um diagnóstico do que falta, do que não vai bem, do que a comunidade docente e discente aponta como desejos. Os princípios definidos devem ser traduzidos na estrutura curricular e nas ações para sua implementação. No processo aqui relatado o valor que principalmente emergiu foi o da liberdade de escolha acadêmica por parte do aluno, tanto com relação à escolha profissional quanto com relação ao seu percurso formativo. Também o do oferecimento de um curso de graduação mais flexível com a possibilidade de atender diferentes desejos e perspectivas dos alunos. A flexibilidade de escolha e a possibilidade que essa fosse feita ao longo da graduação foi um valor central no desenvolvimento da proposta.

Um currículo também não se realiza isolado no âmbito interno da instituição. Ocorre numa sociedade com suas contradições e desafios. Nesse sentido, a escolha pela flexibilidade curricular sempre se debateu com as exigências postas pelas diretrizes curriculares vigentes. Desde as antigas e, em nossa opinião, obtusas diretrizes colocadas pelo Conselho Federal de Química (CFQ, 1975) como as mais novas diretrizes, principalmente as para a formação de professores (Brasil, 2015; São Paulo, 2017), que embora possam ser largamente justificadas foram e ainda são mais restritivas. Sem dúvida, aqui ocorre o embate de uma instituição de pesquisa de uma área básica do conhecimento científico com a tradição de Ensino Superior brasileira deveras profissionalizante.

Ajustes que visam o aprimoramento da proposta são sempre necessários. O processo não termina, é contínuo e exige observação e revisão constantes. No entanto, uma mudança curricular não pode se limitar a uma nova grade curricular. Deve ensejar mudanças que são de natureza cultural, muitas vezes implícitas. Tais mudanças são em si o maior desafio. Práticas de ensino que estejam afinadas com o princípio de um desenvolvimento da autonomia do estudante, que tirem o foco do ensino e o passem para o aprendizado constituem a questão de maior relevância para o momento. Ultrapassar a dimensão da ação docente individual, atuando de forma dedicada mas preso à percepção restrita de sua disciplina para a atuação mais institucional, que nunca perca de vista o todo do curso e a complexidade da formação universitária, é, provavelmente, o caminho necessário.

\section{Notas}

1 Outras áreas da USP apresentam a mesma característica. Um exemplo próximo da área de ciências da natureza é o curso de Ciências Biológicas do Instituto de Biociências. Já outros cursos como os de Bacharelado e Licenciatura em Física e mesmo os cursos de Bacharelado e Licenciatura em Química de Ribeirão Preto são divididos em carreiras distintas e, consequentemente, escolhas definidas na inscrição para o vestibular. Não 
nos cabe aqui uma discussão geral de qual é o melhor modelo. Mais do que refletir diferentes concepções formativas, em especial para o professor, acreditamos que tal diversidade reflete diferentes características e necessidades locais.

2 Ressalta-se aqui que a escolha pela dupla titulação implica um significativo aumento no tempo para término da graduação necessário para a integralização das disciplinas específicas.

3 São emitidos apenas dois diplomas correspondentes aos dois títulos profissionais, o de Bacharel em Química e o de Licenciado em Química. As opções que complementam o bacharelado são certificadas por meio de documento emitido a parte. O diploma de bacharel permite ao egresso obter o registro profissional de químico junto ao Conselho Regional de Química e o certificado das Atribuições Tecnológicas permite o registro profissional de químico industrial.

4 Embora não tenhamos aqui números consolidados, não é raro um bacharel formado no IQUSP retornar à graduação para completar a Licenciatura. Tal fato tem nos indicado que, muitas vezes, a escolha pela docência se dá em um momento de maior maturidade e experiência profissional.

5 Tal modelo era predominante no passado e ficou conhecido com $3+1$. Aqui há um desafio para a montagem da grade horária. Um curso de Química exige conhecimentos básicos de matemática e física que, via de regra, são pré-requisitos para o aluno compreender os conteúdos da sub-área de físico-química, que por sua vez apresentam muitas das bases teóricas para a compreensão de outras sub-áreas da química. Assim, essas disciplinas precisam ser abordadas invariavelmente na primeira metade do curso. O que torna, para a química em especial, um grande desafio romper com a tradição do modelo 3+1. Não é raro encontrar cursos de Licenciatura em Química onde a opção foi tratar mesmo de conhecimentos básicos nos últimos semestres. Para um curso de Licenciatura pura isso pode não ser um grande problema, mas para a nossa realidade foi um grande desafio.

6 Não cabe aqui apresentar com detalhes o projeto pedagógico muito menos a grade curricular dos cursos. Uma informação mais detalhada dos mesmos pode ser encontrada em: <http://www3.iq.usp.br/paginas_view.php?idPagina=85>, acesso em: 17 set. 2018.

7 Uma ação tomada logo no início da implementação foi colocar na grade horária entregue aos alunos do $1^{\circ}$ ano além do horário das aulas um horário destinado aos estudos das disciplinas especificamente. Para o curso integral as aulas foram distribuídas ao longo de todos os dias, de maneira que os alunos entendessem que o curso é realmente integral e não, por exemplo, matutino, caso as aulas fossem distribuídas ao longo da manhã. Para os anos subsequentes essa estratégia já não foi adotada, uma vez que também é desejável que o aluno tenha tempo para estágios, sejam de iniciação científica dentro da universidade, sejam no setor produtivo. No período noturno, como isso não é possível, foi indicado que os tempos para estudos deveriam se concentrar aos sábados ou no contra turno, caso possível.

8 Um egresso do curso de graduação do IQUSP que venha a se matricular no programa de pós-graduação em Química não poderá cursar a disciplina correspondente àquela já cursada na graduação.

9 Não são aceitas como disciplinas eletivas para o bacharel aquelas obrigatórias da licenciatura. Isso foi feito para que o curso de Bacharelado tivesse também uma identidade específica. No entanto, os alunos têm se queixado do tamanho da carga horária ne- 
cessária para a obtenção dos dois títulos e apontado isto como uma razão de grande dificuldade encontrada para completar a licenciatura.

10 Uma importante ação para facilitar a matrícula dos alunos em disciplinas dessa natureza foi um acordo firmando entre os Institutos de Química, de Física, de Matemática e Estatística e de Astronomia e Geofísica para que boa parte das disciplinas obrigatórias de seus cursos tenha uma pequena parte de suas vagas oferecidas como optativas livres para os demais. Tal iniciativa deveria ser ampliada com outras unidades e deveria até se tornar uma política de graduação mais ampla na universidade.

11 Nem todas as disciplinas do núcleo básico do bacharelado compõem o núcleo básico da licenciatura tendo em vista as exigências específicas para esta última. No entanto, é facultado ao aluno cursar tais disciplinas como optativas livres.

12 Há uma diferença entre o núcleo básico de conhecimentos químicos para o curso de Bacharelado e o de Licenciatura. Sete disciplinas obrigatórias para o primeiro, as de conteúdo químico mais avançados, não são obrigatórias para o segundo (Química Analítica III, Biologia Molecular, Bioquímica Experimental, Físico-química III, Espectroscopia, Química Inorgânica II e Iniciação Científica). É questionável se o conhecimento abordado nessas disciplinas não seria importante para a formação de um professor. Em nossa opinião, sim, em boa parte desse conteúdo. No entanto, as crescentes exigências específicas para a formação de professores já citadas impedem que a formação do professor se acrescente à formação do bacharel. Escolhas devem ser feitas e lacunas precisam ser assumidas em prol de novas demandas que também se justificam.

13 Tradicionalmente no IQUSP esse conteúdo era todo abordado em um único semestre dividido em duas disciplinas diferentes, em que uma tratava da estrutura atômico-molecular da matéria, enquanto outra tratava de aspectos gerais das reações químicas. Era essa a organização vigente no curso do período integral. No curso do período noturno foi essa mesma a organização vigente na sua criação em 2003. No entanto, a adaptação curricular feita em 2009 já adotou a proposta aqui apresentada tendo em vista as dificuldades percebidas já naquela época.

14 Não há espaço aqui para aprofundar essa questão. No entanto, ela não pode mais ser desconsiderada pela Universidade pública brasileira, principalmente tendo em vista a triste heterogeneidade da educação básica brasileira e os esforços que a própria Universidade tem feito para se tornar mais inclusiva.

15 Ver texto sobre a BNCC neste volume.

16 Não cabe aqui entrar em detalhes, mas uma alteração digna de nota foi na área de físico-química que já tinha seu conteúdo trabalhado em três disciplinas teóricas e uma disciplina experimental, todas com 4 horas/semana. O conteúdo referente a termodinâmica continuou sendo tratado na primeira disciplina onde foi agregado o conteúdo de eletroquímica. Já o conteúdo de química quântica, que sempre foi tratado na última disciplina teórica, passou para Físico-química II. A terceira e última disciplina teórica passou a apresentar uma breve introdução à termodinâmica estatística, teoria do estado de transição e mecanismos de reação e química de coloides e superfícies. Todo o conteúdo básico de cinética química passou a ser abordado na Química Geral II e não é repetido nas disciplinas de Físico-química.

17 Um ajuste na ementa da disciplina Físico-química III mencionado na nota anterior é um exemplo disso. 
18 No curso integral antes da reforma chegou-se a adotar o conceito de requisito-fraco, onde o aluno poderia se matricular em uma disciplina se tivesse cursado a disciplina requisito e tido nota superior ou igual a 3 , o que não o aprova (a média mínima de aprovação é 5 ) mas o habilita para uma segunda avaliação (recuperação). Tal processo promoveu inconvenientes como o de ter alunos próximos à formatura devendo disciplinas de $1^{\circ}$ ou $2^{\circ}$ ano.

19 O tempo mínimo de conclusão para os ingressantes no curso integral se encerrou em 2017, enquanto para o período noturno se encerra neste ano de 2018. Dos 61 ingressantes no período integral, apenas 5 terminaram o bacharelado em 2017, e 1 completou também a habilitação em Química Tecnológica.

20 É comum docentes de disciplinas subsequentes trocarem informações sobre o que foi ou não tratado em cada uma de suas disciplinas. O que se desejava aqui era uma coordenação mais horizontal.

21 Os rumos a que tomaram a Base Nacional Comum Curricular, em especial no tocante ao conteúdo de Ciências e, sem dúvida em Química, devem aprofundar ainda mais estes problemas, não sendo em nada animador o futuro que se avizinha.

22 Tal iniciativa tem também implicações para o processo de avaliação, uma vez que sendo claro para professor e aluno o que se espera, tem-se claro o que os exames devem cobrar.

23 No IQUSP foi criado neste ano o Grupo de Apoio Pedagógico (GAP) do qual este autor faz parte. Essa inciativa, já existente em diversas unidades da USP, pode ajudar a catalisar as mudanças de estratégias de ensino.

\section{Referências}

ATKINS, P.; JONES, L., Princípios de Química: questionando a vida moderna e o meio ambiente. 3.ed. Porto Alegre: Artmed, 2007.

BERGMANN, J.; SAMS, A. Sala de aula invertida: uma metodologia ativa de aprendizagem, la ed., Rio de Janeiro: LTC, 2018

BORDENAVE, J. D.; E PEREIRA, A. M. Estratégias de Ensino-Aprendizagem. 26.ed. Petrópolis: Vozes, 2005. p.239.

BRASIL, Ministério da Educação. Parâmetros Curriculares Nacionais para o Ensino Médio. Brasília. MEC/SEMTEC, 1999.

BRASIL, Conselho Nacional de Educação. Câmara de Ensino Superior. Resolução 1/02. Institui Diretrizes Curriculares Nacionais para a Formação de Professores da Educação Básica, em nível superior, curso de licenciatura, de graduação plena, Brasília CNE/CEE, 2002a.

BRASIL, Conselho Nacional de Educação. Câmara de Ensino Superior. Resolução 2/02. Institui a duração e a carga horária dos cursos de licenciatura, de graduação plena, de formação de professores da educação básica, em nível superior, Brasília CNE/CEE, 2002b.

BRASIL, Conselho Nacional de Educação. Câmara de Ensino Superior. Resolução $2 / 2015$. Define as diretrizes curriculares nacionais para a formação inicial em nível superior (cursos de licenciatura, cursos de formação pedagógica para graduados e cursos de segunda licenciatura) e para a formação continuada. Brasília CNE/CEE, 2015. 
BRASIL, Conselho Nacional de Educação. Secretaria de Educação Básica. Base Curricular Nacional Comum Curricular para o Ensino Médio, Brasília CNE/CEB, 2018.

BURROWS, A. et al. Chemistry ${ }^{3}$ : introducing inorganic, organic and physical chemistry. Oxford: Oxford University Press, 2009.

CICUTO, C. A. T.; TORRES, B. B. Implementing an Active Learning Environment To Influence Students' Motivation in Biochemistry, Journal of Chemical Education, v.93, p.1020-6, 2016

CONSELHO FEDERAL DE QUÍMICA - CFQ, Resolução Ordinária n.1511 de 12.12.1975.

SÃO PAULO, Conselho Estadual de Educação. DELIBERAÇÃO CEE n.157/2017.

SEERY, M. K., Flipped learning in higher education chemistry: emerging trends and potential directions, Chem. Educ. Res. Pract., v.16, n.4, p.758-68, 2015.

FERREIRA, L. H.; KASSEBOEHMER, A. C., Formação inicial de professores de quimica: a instituição formadora (re)pensando sua função social. São Carlos: Pedro \& João Editores, 2012.

USP, Pró-Reitoria de Graduação, Comissão Permanente de Licenciaturas, Programa de Formação de Professores, 2004. Disponível em: <http://www4.fe.usp.br/wp-content/ uploads/programa-de-formacao-de-professores/programa-de-formacao-de-professores.pdf>. Acesso em: 17 set. 2018.

RESUMO - O presente artigo descreve a mais recente estrutura curricular do curso de graduação em Química do Instituto de Química da USP. Mostra como a opção institucional pela formação de quadros profissionais para atender as demandas da pesquisa científica, do setor produtivo e da educação básica, aliada às características de um instituto de pesquisa e as experiências curriculares anteriores, levou à determinação de princípios que estruturam e organizam o currículo. Dentre tais princípios destacam-se: liberdade acadêmica do aluno na escolha de sua profissão e na definição de seu percurso formativo; uma base sólida de conhecimentos químicos e incentivo a estudos constantes. Por fim, aponta que uma alteração curricular não deve se resumir a uma mudança da grade de disciplinas. O próximo passo envolve uma mudança de cultura que coloca em foco um aprendizado mais ativo por parte do aluno.

PALAVRAS-CHAVE: Ensino superior, Graduação, Currículo, Ensino de Química.

ABSTRACT - This article describes the most recent Chemistry undergraduate curriculum of USP's Institute of Chemistry. We point out how the institutional option for professional training to meet the demands of scientific research, the productive sector and basic education, allied to the characteristics of a research institute and previous curricular experiences, led to some principles that served to structure and organize the curriculum. Among these principles, the following stand out: academic freedom for students to choose their profession and define their formative route; a solid base of chemical knowledge and encouragement for constant studies. Finally, it points out that a curricular change should not be limited to changes in the courses offered. The next step involves a real culture change that focuses on a more active learning process.

KErWORDS: Higher education, Undergraduate education, Curriculum, Chemistry teaching. 
Flavio Antonio Maximiano é doutor em Química pelo Instituto de Química da USP, professor do Departamento de Química Fundamental onde atua na área de Ensino de Química. @- famaxim@iq.usp.br.

Recebido em 24.9.2018 e aceito em 16.10.2018.

Instituto de Química, Universidade de São Paulo, São Paulo, São Paulo, Brasil. 
